\title{
The Role of Traditional Birth Attendants in Family Planning Programs in Southeast Asia
}

\author{
J. Y. Peng
}

Department of Population Planning, University of Michigan, Ann Arbor, Michigan, USA, and International Development Research Centre of Canada, Population and Health Sciences, Regional Office for Asia, Singapore, Republic of Singapore

\begin{abstract}
Peng JY (Dept of Population Planning, University of Michigan, Ann Arbor, MI, USA, and International Development Research Centre of Canada, Population and Health Sciences, Regional Office for Asia, Singapore, Republic of Singapore). The role of traditional birth attendants in family planning programs in Southeast Asia.

Int J Gynaecol Obstet 17: 108-113, 1979

The training and utilization of traditional birth attendants (TBAs) in maternal and child health and family planning programs in Indonesia, the Philippines, Thailand and Malaysia are discussed. Special efforts to organize and train TBAs for family planning in Malaysia are examined in detail. Import factors for successful utilization of TBAs include: (a) definite assignment of functions and tasks, (b) organization of good operational steps and (c) implementation of good supervisory activities.
\end{abstract}

\section{INTRODUCTION}

In rural areas of Asian countries, traditional birth attendants (TBAs), as they have come to be called, ! ay an important role in the health of women. In addition to attending at childbirth, they provide advice and care, both before and after childbirth, and act as folk healers and masseuses. Some TBAs even perform abortions.

TBAs are usually older, married women who have had little or no formal education. They receive their training in midwifery from relatives, friends or other traditional midwives. The compensation they receive for services may be in the form of cash, food or clothing; it is usually not fixed but depends on the client's offer and ability to pay $(1,2,6-8)$.

Because the number of health personnel is frequently inadequate in rural communities of developing countries, for several years health and family

The author is currently Associate Director for International Activities/ East of the International Fertility Research Program, Research Triangle Park, NC, USA. planning officials have felt that TBAs could play a useful role in promoting family planning and maternal and child health (MCH) in their local communities. Being known and trusted by the women in their village, TBAs are in an excellent position to introduce new ideas and practices.

The Southeast Asian countries of Indonesia, Malaysia, the Philippines and Thailand have all made efforts to integrate traditional village midwives into their family planning and $\mathrm{MCH}$ programs. TBAs are called Bidan Kampong or Dukun Bayi in Indonesia, Hilot in the Philippines, Moh Tam Yae in Thailand and Kampong Bidang in Malaysia. Some measure of the potential impact that large-scale use of TBAs could have is indicated by the following figures (5).

There are an estimated 60000 TBAs in Indonesia, 3000 in Malaysia, 32000 in the Philippines and 30 000 in Thailand. In 1971 and 1972, the estimated proportion of all births attended by TBAs and other persons without formal training was $80 \%-90 \%$ in Indonesia, 27\% in Malaysia, 48\% in the Philippines and $75 \%$ in Thailand (4).

All these countries made it their policy to use TBAs to improve $\mathrm{MCH}$ and family planning by training the TBAs and organizing them to work under the supervision of health personnel. However, these countries did not attempt to mobilize more new TBAs; instead they tried to replace TBAs with trained midwives.

This paper describes the general situation of TBA utilization in the national family planning programs of Indonesia, the Philippines and Thailand; and it specifically examines the Malaysian program, with which the author was personally involved from its inception, as an example of organized effort in this endeavor.

In Indonesia, where the $\mathrm{MCH}$ program of the Ministry of Health is responsible for training TBAs, 34110 TBAs had been trained by the end of 1976 , with more than 10000 of them trained in 1976 alone. (Village heads register TBAs who undergo training.) 
The initial training lasts from one to two weeks; thereafter training sessions continue once weekly for the next six months. At the end of the six months, the TBAs sit for an oral examination. Certificates are given for successful completion of the examination. With these certificates, the TBAs need only meet once a week for refresher courses and work meetings (about $50 \%$ attend).

TBAs are trained in hygienic delivery, antenatal and postnatal care and family planning. They are also asked to report births and deaths of infants and mothers. They keep delivery books to record such information as dates, mothers' names, sex of babies, outcome of delivery, etc. Most TBAs in Indonesia are female, except in Bali where there are male TBAs who attend deliveries.

In the past, United Nations Children's Fund (UNICEF) delivery kits were given to Indonesian TBAs. Since no more UNICEF kits are available, the Government is now purchasing locally made Dukun Kits for the TBAs who complete their training. Although there is no longer an incentive program for TBAs, they still help the national $\mathrm{MCH}$ and family planning program. A guide book for $\mathrm{MCH}$ workers, which includes instructions for Dukuns (ie, TBAs), is now being used.

The performance of TBAs as family planning motivators depends upon guidance given by the government midwives, the activities in the clinics and the presence of female doctor in the clinic. An average of 2-3 family planning acceptors per month are recruited by each TBA. Initially, just after training, TBAs usually start with a high number of recruits but this number gradually declines. There is considerable disparity in the performance of various TBAs.

In the Philippines, trained TBAs are integrated to some extent into the health care system operated by the Government. Training has centered on actively practicing TBAs residing in rural areas. Between 1954, when the training program started, and 1974 , a total of 9200 TBAs have been trained by the government program. UNICEF has assisted by providing midwifery kits. It has been proposed to train 5000 more TBAs by 1976 and thereafter 5000 each year from 1977 to 1980 .

The Maternal and Child Health division of the Department of Health is responsible for training TBAs. The Instructor's Guide for Hilot Teaching prepared by this $\mathrm{MCH}$ division has been used from the beginning. It has also been revised from time to time and now includes training on family planning. Some other teaching materials have also been developed and used.

TBAs provide valuable assistance to rural health nurses or midwives by attending to deliveries at home. A TBA brings water, boils the instruments to be used and helps the nurse/midwife and the family in many ways. A TBA visits the postnatal mother and the newborn baby until the baby's cord is off. The TBA also helps organize mothers' classes, refers pregnant mothers to health centers for antenatal care, assists in birth registration, brings children in for immunization, helps in the housekeeping of health centers, motivates mothers to accept family planning and follows up acceptors. TBAs recruit many family planning acceptors at the outset but the number of acceptors decreases with time. Such a situation prevails in countries where TBAs are used.

A research project to train active TBAs as supervisors of other hilots was conducted and proved useful. Another research project using TBAs as outreach contraceptive distributors from house to house in rural areas has been proposed. The national family planning outreach program also uses TBAs for its program.

In Thailand, the Ministry of Public Health recognizes the important role of TBAs in $\mathrm{MCH}$ and family planning, and most deliveries in rural areas are performed by them. With UNICEF assistance, TBAs have been trained in $\mathrm{MCH}$ for the past 15 20 years in an attempt to improve the services they provided. The training of TBAs lasts two weeks and emphasizes sterile techniques, particularly in the handling of the umbilical cord and the newborn baby, information on $\mathrm{MCH}$ and nutrition and, during the past few years, family planning.

The Department of Maternal and Child Health of the Faculty of Public Health, Mahidol University, has completed a research project on the use of TBAs for family planning sponsored by the International Development Research Center. The project proved successful and valuable. Based on the encouraging results of this study, the Family Health Division of the Ministry of Public Health is now expanding the TBA training program in family planning as part of the Government's national program. The plan is to train provincial level trainers first to cover 70 provinces and Bangkok. In each province, three senior nurses and two sanitary inspectors will be trained to train others. The training of these provincial level trainers was completed in 1977, with these five trainers in turn training local auxiliary health staff (nurses and sanitarians) at the district level who will be the local level trainers for TBAs. It is estimated that within two years $40 \%-45 \%$ of TBAs will be trained for family planning and $\mathrm{MCH}$. To cover all available active TBAs (about $80 \%$ of total), the training may be prolonged to 1980 . 
Trained TBAs will devote $50 \%$ of their time to family planning and the other $50 \%$ to other activities depending upon provincial needs. Excellent flipcharts and motivation kits have been developed for use by TBAs in motivating mothers.

\section{MALAYSIAN TBA TRAINING PROGRAM}

In Malaysia, the National Family Planning Board (NFPB) and the Ministry of Health began training TBAs in 1969. The three-week training program included one week on maternity care, one week on family planning and one week of actual experience with local health authorities. A UNICEF delivery kit was given to each TBA who completed the training. Trained TBAs were placed under the supervision of the local health authority and requested to record deliveries, report to local health authorities, bring delivery kits for examination by supervisors and get supplies of consumable items.

Between 1969, when the three-week training program for TBAs was started, and the end of 1976, a total of 1645 TBAs were trained in 84 training sessions. This type of training will be continued to cover as many TBAs as can be recruited.

In January 1972, The National Family Planning Board started a special project to organize and utilize TBAs for the national family planning program. TBAs were selected for this special project by local nursing supervisors from among those who underwent the three-week training course in 1969 and 1970. TBAs were then trained for family planning in a specific manner.

The training period is short-three days-and specific to the tasks that Bidans will be expected to perform. Basic information is first given through brief lectures, followed by verbal questioning to confirm understanding. Primarily, however, the emphasis is on learning-by-doing and role-playing. During the training session, each Bidan is assigned to a clinic and to a supervisor at that clinic who will oversee and evaluate her performance as long as she is in the program. The supervisor and the Bidan work together throughout the training period so that they can establish a good relationship, which is felt to be essential to successful performance by the Bidan (3, 4).

The project gradually expanded. By 1976, 280 selected TBAs had been trained specifically for the family planning project, and 168 of them were still working actively in the project.

The project was supported by the US Agency for International Development (AID) through the University of Michigan until 1974 when it was taken over by the UN Fund for Population Activities (UNFPA), which provided financial support from 1975 onward.

The following steps describe the operation of the project.

\section{Designated functions of TBAs}

TBAs were requested to perform two main functions:

1. to recruit new acceptors and to encourage the previous program dropouts to return for family planning, and

2. to resupply oral contraceptive (OC) pills.

TBAs were also asked to support $\mathrm{MCH}$ services by bringing prenatal mothers to the antenatal clinic, attending deliveries with qualified government midwives and then bringing postpartum mothers to the MCH clinic for family planning.

\section{System of operation}

Two types of simple, concise coupons were designed for facilitating program operations and for efficient data collection. There were yellow coupons for recruiting acceptors and green coupons for resupplying OCs. The initial supply of OCs was distributed by clinic nurses to those with yellow coupons, resupplies were distributed by Kampung $\mathrm{Bi}$ dans to those with green coupons. The operational system includes:

1. Recruitment of family planning acceptors by TBAs. The TBAs are given yellow Initial Acceptance Coupons (with their TBA numbers and clinics stamped on them) with which they motivate village women to accept family planning. They are particularly encouraged to motivate during contacts with antenatal and postnatal women. When the TBA encounters a potential family planning acceptor, she first tries to discover the women's attitudes toward family planning. In her motivational talk, the Bidan: (a) creates an awareness of the availability of family planning; (b) mentions that spacing of pregnancies is beneficial to the mother's and children's health and (c) suggests that family planning helps to raise the standard of living, gives the mother a better chance of educating her children and creates a happy family environment.

2. Distributing Initial Acceptance Coupons. If after their discussion, the woman decides she would like to practice family planning, the TBA gives her a yellow Initial Acceptance Coupon and tells the woman to take it to the health center/family planning clinic on a given day, when the nurse will see her and give her a one month's supply of contraceptives. The acceptor should bring her Identity Card 
with her to the clinic. (In Malaysia each person reaching age 12 is issued an Identity Card and an Identity Card Number.) The Identity Card tells the person's name, sex, date and place of birth and present address.

3. Visits of TBA acceptors to the family planning clinic. The client takes her yellow Initial Acceptance Coupon to the health center clinic on the appointed day and is seen by the nurse. All acceptors are registered and screened. They receive a method of contraception, six green Resupply Coupons and an appointment card. The nurse explains to the acceptor that she should contact her TBA each month to exchange a green coupon for another month's supply of her contraceptive method.

4. Resupply by TBAs using green coupons. Before the acceptor completes the first month's supply of contraceptives given her by the nurse, she takes the green Resupply Coupon to her TBA, who gives her another month's supply of contraceptives. If the acceptor anticipates being away for a few months, the TBA may give her up to six months' contraceptive supply. If the TBA gives the acceptor three months' supply, she must receive three green Resupply Coupons in exchange. If the acceptor complains to the TBA of side effects from the contraceptive method, the TBA is to give no medical advice. She will instead give the acceptor the clinic dates when she can return to the NFPB clinic and consult the nurse about the side effects and a possible change of method.

At the end of six months, when the client no longer has any green Resupply Coupons left, the acceptor is to report back to the health center clinic for a routine checkup, to see if she has been taking her contraceptive method correctly or if she has any complaints. If the acceptor is happy with her contraceptive method, she is then given another month's supply and five green coupons so she can obtain her next five months' supply from her TBA. She is thus covered for another six months.

5. Failure to come for resupply. If, however, for some reason during the course of the six months the woman has not reported back to the TBA for her monthly contraceptive resupply, the TBA will contact the woman to inquire why she discontinued. At that time, the TBA will try to reassure the woman and motivate her to resume her method of contraception. If the acceptor has complaints of side effects, the TBA will advise her to see the health staff at the health center. The TBA may even accompany her there.

6. Monthly meeting between TBAs and nurses at the NFPB clinic or health center. The TBA must come to the clinic each month on the appointed date for a meeting with her supervising nurse. She will bring to this meeting all the green coupons she has received this month in exchange for contraceptive supplies, her remaining stock of contraceptives and yellow coupons, her Delivery Book and her midwifery kit. At the meeting, the TBA will discuss with the nurse whatever difficulties she has encountered, and the nurse will inform her how many women came to the clinic with yellow coupons given to them by that Bidan. The nurse will restock the TBA's supply of yellow coupons and contraceptives and will give her a list of NFPB dropouts in her area whom the TBA should try to remotivate (giving them a yellow coupon if she succeeds in remotivating them).

Each time she attended a delivery, the TBA will have recorded the delivery date with mother's name and Identity Card number in her Delivery Book. At the monthly meeting, the nurse copies down the Identity Card numbers of the women the TBA delivered during the past month and reminds the TBA to recruit these postpartum women for family planning.

The nurse also asks the reason why certain acceptors have not received resupplies. If the TBA does not know why, the nurse asks her to visit those acceptors and find out. The TBA then receives her monthly allowance. We found the above steps very satisfactory, not only for operation purposes but also for training.

\section{Performance target}

We hoped that each TBA would recruit five new acceptors a month. This target was not reached, although some recruited more.than ten acceptors a month and some none, which resulted in an average number of two new acceptors a month. The important part is the resupply of pills for those mothers who already accepted the initial supply from the clinic nurses. As the project progresses, the number of mothers requiring resupply increases. A TBA in Malacca reached a high of 110 mothers for resupply. The problem here is the workload of this one TBA who has to resupply so many mothers. One of the TBAs persuaded the mothers to have tubal ligations or tried to persuade the husbands to have a vasectomy to reduce the number of resupply. She also tried to give 3-6 cycles of pill resupply at one visit. The optimum number of active users one TBA can satisfactorily supply should be carefully studied.

\section{Compensation}

What would be the most reasonable way to compensate the TBAs for their work? Should compen- 
sation be in the form of incentive payment, salary, allowance, piecework payment or a combination of these? Because of the possible risks of piecework payment, a flat allowance was paid to each TBA each month (M\$30 and about US\$13 a month). A bonus-type incentive payment was made periodically according to performance measured by the number of new acceptors recruited, the number of resupplies of contraceptives to mothers and the assessment of the TBA's performance by her supervisory nursing personnel. The monthly allowance was also increased for TBAs with excellent performance records. Other than material rewards, moral support from headquarters people and supervisory personnel has been emphasized, with TBAs and supervisors working as a family team.

\section{Supervisory channel}

The most important supervisory channel was a monthly meeting designed for working purposes and for receiving allowances by the TBAs from their supervisors at the clinic. The steps for the monthly meeting are clearly designed and effectively carried out. It was also suggested that supervisors visit the TBA's home once a month, but this was not done. There seems to be no need for these home visits because some TBAs come to the clinic more than once a month to see nurses and to get more supplies. Through this working relationship and personal contact, a mutual understanding between the TBA and the supervisor is firmly established and is considered to be one of the most important factors for the program.

\section{Assessment of a TBA's individual performance}

The routine assessment of TBA performance is made through the coupon sent in to the clinic and then to the headquarters. The number of acceptors recruited and the number of resupplies distributed are recorded by the individual TBA. If a TBA shows no performance, she gets a warning. If she continues to perform unsatisfactorily, she is dropped from the project. On the other hand, if a TBA does a good job, she will be eligible for a bonus and increased allowance. A semiannual meeting includes refresher training to reassure the performance of TBAs, and their activities are continually evaluated.

At this follow-up meeting, the amount of bonus for each TBA is decided, and the amount of increase of allowance is also suggested and the bonus is given right at the meeting place. If the TBAs performed well, they are asked to tell their colleagues how they did so well. Those who did not perform well are asked to describe their difficulties and problems.
From our experiences, we found that those who received a bonus and increased allowance continued to perform well.

On the average, each TBA recruited two acceptors a month, ranging from 0 to 20 acceptors, depending on the state and the duration of the project operation.

Another important aspect is the number of continuing users (caseload) for each TBA. The number of acceptors recruited by a TBA and the caseload for each TBA differ by state and by individual TBA. As of April 1975, the average current caseload for each TBA ranged from 12 in Perak, where the program had been in operation only three months, to 65 in Malacca, where it had operated for 36 months.

Almost $100 \%$ of the women surveyed received their initial coupons from TBAs; only $0.3 \%$ said that they got their coupons from their friends and not directly from the TBA.

Seventy-eight percent of the women said that the initial coupon was given to them at their homes, $18 \%$ of them got it at the TBA's house, $2 \%$ of the women got it at the meeting place, and the remaining $2 \%$ got it at the market or other places.

After receiving their initial coupons from TBAs, $50 \%$ of the women came to the clinic for family planning services within one week, $13 \%$ came between one and two weeks, $14 \%$ came between two and four weeks, $16 \%$ came between one and three months and $5 \%$ visited the clinic more than three months after receiving the coupon.

More resupplies of pills are distributed by TBAs who visit the client's home than TBAs who have patients visit their homes. The TBA must remind herself to visit her clients within an appropriate time for a resupply.

The number of women who would actually come to the clinic to receive family planning services after their deliveries were attended by our project TBAs was a major concern. The preliminary data reveal that $20 \%$ of women whose deliveries were attended by our project TBAs visited the clinic for family planning services, ranging from $10 \%$ to $29 \%$ for each state.

\section{CONGLUSIONS}

The author has introduced programs for using TBAs in family planning and $\mathrm{MCH}$ in the four countries in Southeast Asia, whose circumstances, problems and policies in dealing with TBAs were similar. These countries cannot ignore the existence of TBAs, nor can they eliminate TBAs because of 
their numbers and their popularity with rural people. Therefore, the ideal solution was to involve TBAs in the health care system by training and using them in areas where trained health manpower is scarce.

Once it is decided to utilize TBAs, they must be used in the best way possible. Key factors for successful utilization of TBAs include (a) definite assignment of functions and tasks to them, (b) organization of good operational steps and (c) implementation of good supervisory activities. Incentive programs for TBAs may be effective in the beginning, but not on a long-term basis. TBAs should be involved in the government health care delivery system and should be made part of the system in order for them to give of their best. After all, TBAs are fading out and are being replaced by new schooltrained midwives. Our efforts are to make the best use of TBAs until such time as the rural areas are adequately covered by qualified health manpower. In this transitional period TBAs can prove very useful.

\section{REFERENCES}

1. Chen PCY: An analysis of customs related to childbirth in rural Malay culture. Trop Geogr Med 25:197, 1973.

2. Peng JY, Nor Laily bte Abu Bakar, Ariffin bin Marzuki: Village midwives in Malaysia. Stud Fam Plann 3(2):25, 1972.
3. Peng JY, Ross-Larson S, Subbiah M: Utilization of Traditional Birth Attendants (Kampong Bidans) for Family Planning in Malaysia, A Working Manual for Nurses, '2nd edition. National Family Planning Board, Malaysia, and University of Michigan, Ann Arbor, MI, January 1974.

4. Peng JY, Srisomang K, MacIntyre R (eds) : Role of Traditional Birth Attendants in Family Planning, Proceedings of an International Seminar Held in Bangkok and Kuala Lumpur, 19 .26 July 1974 (IDRC-039e). International Development Research Centre, Ottawa, November 1974.

5. Rogers EM, Solomon DS: Traditional midwives and family planning in Asia. Stud Fam Plann 6(5):26, 1975.

6. The Role of the Traditional Midwife in the Family Planning Program, Report of National Workshop to Review Researches into Dunkun Activities Related to $\mathbf{M C H}$ Care and Family Planning, Jakarta, Indonesia, 31 July-2 August 1972.

7. Verderese MDL: Consultation on the Role of Traditional Birth Attendant in MCH and Family Planning, Geneva, 13.20 March, 1973. Report of Review and Analysis of Information and Data on Traditional Birth Attendants World Health Organization, Geneva, nd.

8. Verderese MDL, Turnbull LM: The Traditional Birth Attendant in Maternal and Child Health and Family Planning: A Guide to Her Training and Utilization. World Health Organization, Geneva, 1975.

\section{Address for reprints:}

International Fertility Research Program Research Triangle Park, NC 27709

USA 